\title{
Excretion of Individual Unconjugated 17-Oxosteroids by Normal Female Subjects
}

\author{
By T. FeHER and E. Poteczin \\ From the $1^{\text {st }}$ Department of Medicine, University Medical School, Budapest, Hungary
}

(Eingegangen am 3. Oktober 1967)

A method has been described for the determination of individual unconjugated 17-oxosteroids in human urine. The procedure involves the immediate extraction of the sample, purification steps and a paper chromatographic separation of steroids. The 17-oxosteroids were evaluated by a Zimmermann-reaction in situ on the paper, elution of chromogens and spectrophotometry. Values for the excretion of unconjugated metabolites by healthy female subjects under basal conditions, following corticotrophin and metopirone stimulation, and after administration of testosterone-propionate were also presented. Only very low levels and a preponderance of the $5 \beta$-reduced metabolites were observed in the urines studied.

Es wird eine Methode für die Bestimmung der einzelnen unkonjugierten 17-Oxosteroide in Menschenharn beschrieben. Das Verfahren besteht in der direkten Extraktion der Probe, Reinigungsschritten und einer papierchromatographischen Trennung der Steroide. Die 17-Oxosteroide werden bestimmt durch eine Zimmermann-Reaktion in situ auf dem Papier, Elution der Farbstoffe und Spektrophotometrie. Werte für die Ausscheidung unkonjugierter Metabolite bei gesunden weiblichen Probanden unter Normalbedingungen, nach ACTH- und Metopiron-Stimulation und nach Applikation von Testosteronpropionat werden ebenfalls angegeben. Nur sehr geringe Mengen und ein Uberweigen der $5 \beta$-reduzierten Metabolite werden in den untersuchten Harnen beobachtet.

Earlier observations on the androgen metabolites of human urine refer to the total amounts of individual 17-oxosteroids, representing the sum of the free and esterified metabolites (1). Some recent methods are related to the fractionation of glucuronides and sulphates $(2,3)$. Only fragmentary data are available on the excretion of individual unconjugated 17-oxosteroids by humans (4-7).

The occurrence of free etiocholanolone ${ }^{1}$ ) in the plasma of subjects with "etiocholanolone-fever" has been reported in the literature (8-10). These publications contain merely references and no firm data on the patterns of unconjugated 17-oxosteroids in the urine of patients with the syndrome.

In the course of our study on cases of etiocholanolonefever the 17-oxosteroids were determined simultaneously in plasma and urine (11). In the present communication the procedure and the normal values for individual free 17-oxosteroids in urine measured under basal conditions and following administration of corticotrophin (ACTH), metopirone or testosterone-propionate are described.

\section{Method}

The procedure for the determination of unconjugated steroids in urine utilizes the main steps involved in a previous technique for measuring the amount of individual 17-oxosteroids following hydrolysis, i. e. those excreted mainly as conjugates (12). In order to avoid the spontaneous hydrolysis of conjugates, the determinations were made immediately after the collection of urine. A $200 \mathrm{~m} l$ aliquot of $24 \mathrm{~h}$ urine was extracted three times with $100 \mathrm{ml}$ of peroxide-free ether. Emulsions were broken by adding a few $\mathrm{ml}$ of ethanol. The combined extracts were washed with $40 \mathrm{ml}$ of $\mathrm{N} \mathrm{NaOH}$ and $40 \mathrm{ml}$ of water, dried over anhydrous $\mathrm{Na}_{2} \mathrm{SO}_{4}$ and evaporated. The residue was dissolved in absolute ethanol, then aliquots equivalent to 50 to $100 \mathrm{ml}$ urine, together with reference standards, were applied to Whatman No 1 paper.

1) Synonyms in the publication: HOE: $3 \alpha, 11 \beta$-dihydroxy-5 $\beta$-androstan-17-one, 11-OH-etiocholanolone. HOA: $3 \alpha, 11 \beta$-dihydroxy$5 \alpha$-androstan-17-one, 11-OH-androsterone. OE: 3 $\alpha$-hydroxy$5 \beta$-androstan-11, 17-dione, 11-keto-etiocholanolone. DEA: $3 \beta$ hydroxy-androst-5-en-17-one, dehydroepiandrosterone. E: $3 \alpha-$ hydroxy- $5 \beta$-androstan-17-one, etiocholanolone. A: $3 \alpha$-hydroxy$5 \alpha$-androstan-17-one, androsterone. Testosterone: 17 $\beta$-hydroxyandrost-4-en-3-one.
The paper was then impregnated with $30 \%$ propylene glycol in methanol, and the steroids were chromatographed in the solvent system, ligroin (b. p. $\left.100-130^{\circ}\right) /$ benzene/methanol $(130: 60: 10 \mathrm{v} / \mathrm{v})$. For the quantitative determination, Zimmermann-reaction was carried out in situ, the steroid chromogens were eluted and measured spectrophotometrically (12). The values were expressed in androsterone equivalents.

The general basis of the method has been eperimentally verified and the results were described previously (12). Furthermore, to check that no spontaneous hydrolysis of steroid conjugates occurred, $200 \mu \mathrm{g}$ dehydroepiandrosterone-sulphate were added to $200 \mathrm{~m} /$ specimens of urine, and then processed as described above. No free DEA was observed by subsequent chromatography and Zimmermann-reaction. According to the experiments, the sensitivity of the method was $3 \mu \mathrm{g} / 24 \mathrm{~h}$ determined by the lowest quantitative limit of evaluation and by the volume of urine processed. Recovery of DEA, E and A added in 3 to $30 \mu \mathrm{g}$ amounts to $200 \mathrm{~m} /$ aliquots of urine in six experiments was $86 \pm 4 \%$ (mean \pm S. E.). The structure of the steroids was supported by paper chromatography and thin-layer chromatography on silica gel $G$, by various colour reactions and by the formation of derivatives (12-14).

Normal individuals in the present study included females between 16 and 38 years of age. These subjects were members of the staff or patients exhibiting no endocrine abnormalities. The menstrual cycle was disregarded during the experiments.

Excretion of unçonjugated 17-oxosteroids was determined,

1. under basal conditions,

2. following stimulation of adrenals by two subsequent injections of $80 \mathrm{U}$ ACTH (Exacthin, RrCHTER, Budapest) i. m. and

3. during oral administration of $6 \times 0.5 \mathrm{~g}$ metopirone (CIBA, Basel) for two days (15). Furthermore,

4. testosterone-propionate (Androfort, RiCHTER, Budapest) was administered in $30 \mathrm{mg} /$ day dose levels $\mathrm{i}$. $\mathrm{m}$. for 5 consecutive days and the urine collected on the last day of therapy (16).

\section{Results}

The amounts of individual free 17-oxosteroids in the urine of female subjects under basal conditions and after the administration of ACTH, metopirone or testosterone-propionate are shown in Table 1. For comparison, the mean values of conjugates (including free steroids) calculated from data reported in detail previously (17) are also indicated.

According to the present investigation, the excretion of individual unconjugated 17-oxosteroids varied from undetectable amounts to $44 \mu \mathrm{g} / 24 \mathrm{~h}$, the highest individual value under physiological conditions. There was a 
predominance of $5 \beta$-steroids in the urine of the female subjects studied (mean $5 \beta / 5 \alpha$ ratio 6.0). Following administration of ACTH, metopirone or testosterone the urinary output of free steroids increased, as has been routinely observed for conjugates $(1,16)$. It is noteworthy that injection of testosterone-propionate enhanced the excretion of $\mathrm{HOE}$ or $\mathrm{OE}$ and that practically no HOA was isolated from urines irrespective of the condition of measurement. As shown further in Table 1 , the $5 \beta / 5 \alpha$ ratio of unconjugated metabolites generally increased after ACTH and metopirone stimulation or following testosterone.

As regards unconjugated $\mathrm{E}$, the steroid was present in almost every urine sample (mean basal $10 \mu \mathrm{g} / 24 \mathrm{~h}$ ) and its amount did not exceed $79 \mu \mathrm{g} / 24 \mathrm{~h}$ after any treatment.

Tab. 1.

Excretion of individual unconjugated 17-oxosteroids by normal female subjects under physiological conditions and after the ad-
ministration of ACTH, metopirone or testosterone-propionate

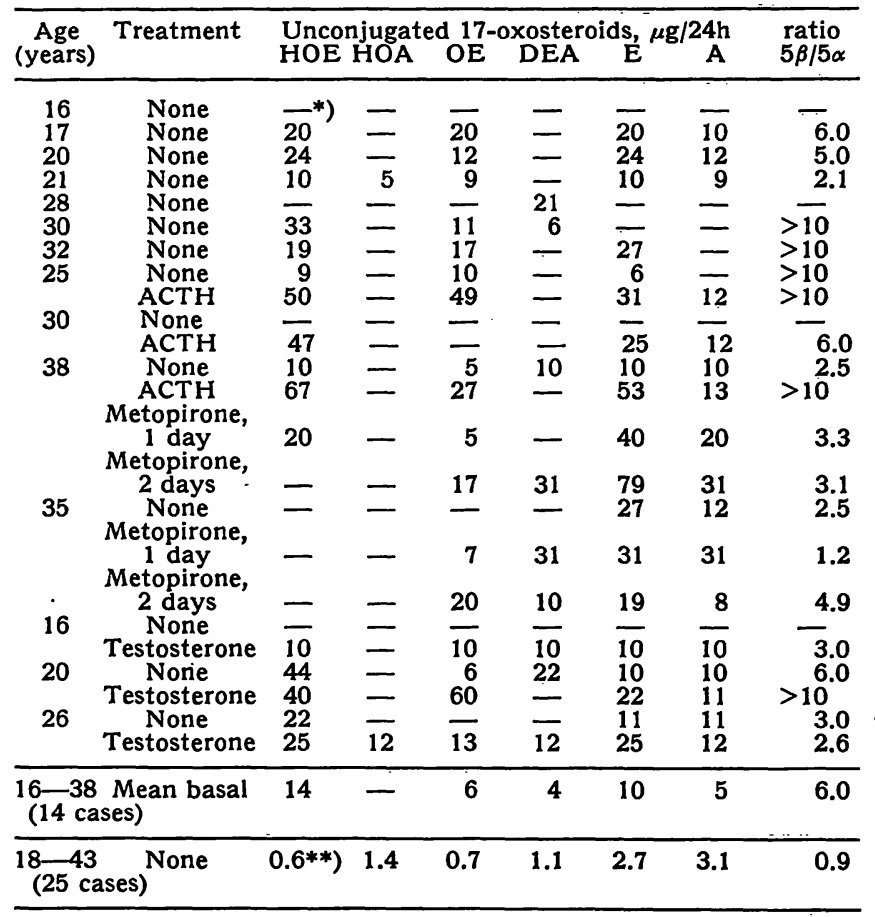

*) Not detectable by the method employed.

**) Mean values of conjugates (glucuronides + sulphates), in mg/24h.

\section{Discussion}

To our knowledge, only fragmentary data are available on the excretion of unconjugated 17-oxosteroids in human urine. These refer only to one or other of steroid metabolites (4-6), or to the $\mathrm{C}_{19} \mathrm{O}_{3}$ and $\mathrm{C}_{19} \mathrm{O}_{2}$ fractions without any separation of individual components (7).

In the present study, the individual free 17-oxosteroids were determined in the urine of normal female subjects under various conditions. Only minute amounts of the steroids could be detected.

It is known that the $3 \alpha(\mathrm{OH})$-steroids are conjugated chiefly as their glucuronides, and the $3 \beta(\mathrm{OH})$-steroids as their sulphate conjugates in urine $(1-5)$. Thus it can be concluded that the mode of conjugation is determined by the structure of the molecule. Conjugated $\mathrm{HOE}, \mathrm{HOA}$ and $\mathrm{OE}$ are the main 11-oxygenated 17-oxosteroids in urine (1) and, according to the present study, no HOA but significant amounts of HOE and $\mathrm{OE}$ are detectable in the free fraction. These observations support the hypothesis that not only the mode but the effectivity of conjugation is determined by the constitution of steroid metabolite.

Although largely identical amounts of $5 \beta$ - and $5 \alpha$ reduced 17-oxosteroids are excreted as conjugates $(1,2,17)$, a preponderance of the free $5 \beta$-steroids in the urine of female subjects was observed here under physiological conditions. Furthermore, the $5 \beta / 5 \alpha$ ratio of unconjugated steroids increased when the endogenous production of precursors was stimulated by ACTH and metopirone, or following the administration of exogenous testosterone, which is one of the common precursors of 11-deoxy-17-oxosteroids.

From the findings it may be concluded that the androgen metabolism in female subjects is characterised by a reduced activity of $5 \beta$-conjugation and/or a certain renal selectivity towards the appearance of unconjugated $5 \beta$-steroids in urine.

We wish to thank Prof. K. Junkmann, Schering AG Berlin, for the courtesy of a gift of dehydroepiendrosterone sulphate.

\section{References}

1. Hübener, H. J. and W. H. StadB, Biochemie der Nebennierenrinden-Hormone. Thieme, Stuttgart (1965). - 2. BAulreu, E. E. and G. Mrchaud, Bull. Soc. chim. biol., Patis 43, 885 (1961). 4. Schenker, S., H. Wilson and A. Spickard, J. Clin. Endocr., Springfield 23, 95 (1963). - 4. Jaoude, F. A., E. E. BAulieu and N. F. JAYLE, Acta endocr., K'hrn 26, 30 (1957). - 5. SchNeIder, J. J. and M. L. Lewbart, Recent Progr. Hormone Res., N. Y. 15, 201 (1959). - 6. GoLD, J. J. and S. GoldBerg, Fertility and steril., N. Y. 14, 73 (1963). - 7. DÄssLER, C. G., Acta endocr. K'hvn 49, 283 (1965). - 8. Bondy, P. K., Cohn, G. L., W. HERR- mann, W. and K. R. CRispeld, Yale J. Biol. 30, 395 (1958). - 9. Bondy, P. K., G. L. Cofin and P. B. Gregory, Medicine, Baltimore 44, 249 (1965). - 10. Huhnstock, K., D. KuHN and G. W. Oerted, Dtsch. med. Wschr. 91, 1641 (1966). - 11. FehÉR, T. and L. HALMY, Europ. J. Steroids, in press. - 12. FeHÉr, T., Clin. chim. Acta Amsterdam 14, 83 (1966). - 13. Fehér, T., Mikrochim. Acta 105 (1965): - 14. FehÉr, T., J. Chromatogr. 19, 551 (1965). 15. FehÉr, T. and O. KoREF, Europ. J. Steroids 2, 3 (1967). -16. Hoxró, I., Acta med. Hung. Budapest 20, 237 (1964). 17. Fehér, T., Clin. chim. Acta Amsterdam 14, 91 (1966).

Dr. T. Fehér, Ph. D. Budapest VIII Korányi S. 2/a. Hungary 